\title{
ALFONSO REYES Y ESPAÑA
}

\section{INTRODUCGIÓN}

Alfonso Reyes publica en París (1911) sus Cuestiones estéticas. Es entonces un mozo de veinte años y sus ensayos son de una rara madurez: los puntos de vista de la adolescencia apenas debieron rectificarse en los años de plenitud ${ }^{1}$. Hay en ellos alguno que nos toca muy de cerca, sobre ello volveré, pero ahora quiero recoger unas palabras del Prólogo de Francisco García Calderón: "Defiende el ideal español, la armonía griega, el legado latino, en un país amenazado por turbias plutocracias"”. La afirmación es una postura vital que se justificaría en un proyecto de trabajo realizado con heroica perseverancia y que, con los meandros que la vida impone, mantuvo rectamente hasta el fin de sus días. Después, la ida a Europa le exigió otros compromisos, y no desechó el pasado indígena de México que, en Madrid (1915), le vio alumbrar la Visión de Anáhuac (1519), publicada en San José de Costa Rica en $1917^{3}$, y que le dio no pocas alegrías: se tradujo al francés (1927), al alemán (1932), al inglés (1932 y 1950), y al checo (1937). Suum cuique: nuestros viejos cronistas están bien presentes, pues ellos transmitieron una deslumbradora imagen del México antiguo. Después de todo esto, letras y más letras de México y de América. Pero los amores primeros son los que Gar-

${ }^{1}$ Los ensayos son de 1908-1910 (Alfonso Reyes, Obras completas, t. I, p. 10). A lo largo de este trabajo, mis referencias a los estudios y ensayos del autor mexicano se harán a sus Obras completas, editadas en las Letras mexicanas del Fondo de Cultura Económica (1955-1966). Citaré, simplemente, O.C. y, si no hay posible confusión, con el número del tomo, en caracteres romanos, y la página, en arábigos. Otras obras de A. R. van citadas por extenso.

${ }^{2}$ O.C., I, 12.

${ }^{3}$ O.C., II, 10 
cía Calderón descubre. Son los que -forzado por las circunstancias- en 1913 lo llevan a Francia y un año después a España. donde permanece hasta $1924^{4}$, donde tanta tierra se pegó a su: raíces y con ella marchó cuando el árbol fue transplantado.

En 1924 publica Calendario y escribe su biografía en clave. Lé puede descifrar un lector que sepa la historia del héroe, pero qut sepa aquellos versos que se fingieron de Alfonso el Sabio. E hombre, ganado por España, si es que no fue siempre español escribe su Romance viejo:

Yo salí de mi tierra, hará tantos años, para ir a servir a Dios. Des de que salí de mi tierra me gustan los recuerdos.

En la última inundación, el río se llevó la mitad de nuestri huerta y las caballerizas del fondo. Después se deshizo la casa y s dispersó la familia. Después vino la revolución. Después, nos l mataron...

Después, pasé al mar, a cuestas con mi fortuna, y con una es trella (la mía) en este bolsillo del chaleco.

Un día, de mi tierra me cortaron los alimentos. Y acá, se desa tó la guerra de los cuatro años. Derivando siempre hacia el sur, $h$ venido a dar aquí, entre vosotros.

$\mathrm{Y}$ hoy, entre el fragor de la vida, yendo y viniendo - a rastra con la mujer, el hijo, los libros-, ¿qué es esto que me punza y brc ta, y unas veces sale en alegrías sin causa y otras en cóleras ta justas?

Yo me sé muy bien lo que es; que ya me apuntan, que van nacerme en el corazón las primeras espinas ${ }^{5}$.

\section{LOS PRIMEROS CONTAGTOS}

Alfonso Reyes era hijo del general Bernardo Reyes, "goberni dor ateniense de un estado mexicano, rival de Porfirio Díaz, । presidente imperator" 6 . Don Bernardo era culto, protegió lí

${ }^{4}$ En agosto llegó a San Sebastián y en octubre se trasladó a Madrid (I 7). Para la bibliografía de Alfonso Reyes, véase Alicia Reyes, Genio y figu de Alfonso Reyes, Buenos Aires, 1976.

${ }^{5}$ II, 359. Cf. el poema "9 de febrero de 1913" en su Obra poétic México, 1952, p. 122. Y léase la Oración del 9 de febrero en Alfonso Reyes. Homen je nacional, México, 1981, pp. 95-111. Véase "El hombre y su mundo", ' Andrés IdUARTe, en el libro Alfonso Reyes: Vida y obra. Bibliografía. Antologr New York, 1956.

${ }^{6}$ O. C., I, 12. 
letras, reeditó el Ariel de Rodó, fue amigo de Rubén ${ }^{7}$, tuvo una vida más que azarosa y un desastrado fin: en rebelión contra Madero, fue muerto cuando intentaba penetrar en el Palacio Nacional (9 de febrero de 1913) ${ }^{8}$. No es mucho aventurar si pensamos que Alfonso aprendió del padre el trato con los libros. Lo mismo que heredó de él el "arielismo" literario ${ }^{9}$ que fraguó en sus espléndidos ensayos. Pero, desde México, ya fue mucho que el mozo de pocos años se sintiera atraído por la gran literatura de un pueblo hermanado con el suyo en el espíritu y en la lengua. Lógicamente, la primera admiración se hizo en lo que - desde lejospodía saberse. Y Alfonso Reyes quiso a España por las dos manifestaciones de su genialidad: la literatura popular y la literatura culta. Ya en 1910, el refranero y el romancero viejo le inspiran líneas de entusiasmo ${ }^{10}$. No creo que Menéndez Pelayo fuera ajeno a estas consideraciones primerizas: el mismo modo de llamar viejos a los romances más antiguos, me hace pensar en el famoso Tratado; por don Marcelino tuvo siempre un gran respeto $\mathrm{y}$, cuando muchas cosas habían pasado y no pocos intereses habían desvirtuado la verdad, escribió su Reconciliación de Menéndez Pelayo (1944), llena de ponderación ${ }^{11}$. Esta era la literatura po-

7 Véase el cap. 65 de la Vida del poeta nicaragüense, donde cuenta cómo le ayudó en ocasión de encontrarse con apuros económicos. Rubén, nunca mezquino, le dedicó un artículo al día siguiente de su muerte.

${ }^{8} \mathrm{Cf}$. Diccionario Porría. Historia, biografía y geografía de México $\left(2^{\mathrm{a}} \mathrm{ed}\right.$.), México, 1965. En Parentalia (México, 1958), hizo Alfonso Reyes la biografía paterna, pero no narró el final, sustituido por una lírica evocación, Incipit vita nova; sin embargo, al final del volumen, hay una esquemática cronología en la que se relatan los hechos de diciembre de 1912 al 9 de febrero del año siguiente (p. 184). Tampoco se cuentan los acontecimientos en el Diario. 19111930 (Universidad de Guanajuato, 1969).

9 Acerca de este "arielismo", véase su exposición sobre el influjo de Rodó en la juventud mexicana (IDUARTE, op. cit., p. 23).

10 " Donde el grande espíritu del pueblo español [...] se derrama y vierte en la más franca de las alegrías y en la más benigna de todas las sabidurías del vivir [es en los proverbios y sentencias vulgares]" (I, 164), "El pueblo que ha sabido crear el romancero viejo, ese género de belleza incomparable y superior [...]" (I, 165), "el romance viejo español es, en su género, una creación artística tan excelsa como los coros de la tragedia griega" (XI, 131).

11 "Don Marcelino, en su operación viva sobre la historia y la crítica, acabó en liberal; para lo cual, naturalmente, no necesitaba renegar de sus creencias, pues su humanismo nunca entró en inútil conflicto con su sobrehumanismo" (IX, 409). Como dijo Juan Ramón: "Alfonso Reyes, salvador de todo lo salvable". También HenríQuez Ureña, el fraternal amigo que tanto significó en su vida, defendió lo mucho, y bueno, que hay en don Marcelino frente a alguna arbitrariedad de Azorín (En la Orilla. Mi España, México, 
pular que Alfonso Reyes conocía, pero con ella habría de hermanarse aquella epopeya que son los Episodios nacionales en su primera serie: las gestas inacabables, el heroísmo a raudales, la pasión patriótica. El niño del lejano Monterrey no podía abandonar la lectura y se "olvidaba hasta de comer", pero encontró un rincón de paz bajo la enorme mesa del comedor y ya nadie volvió a interrumpirle ${ }^{12}$.

En estas inclinaciones había descubierto la tradición. Tal vez el joven Reyes no la formulara como la formulamos hoy, pero estaba en el buen camino. Sería Menéndez Pidal quien viniera ć descubrir lo que la tradición es en la historia literaria y no po dríamos separar el'saber posterior de Alfonso Reyes de la doctri na de aquel hombre al que gustó llamar maestro o maestro de todos Hasta 1919 no se formuló de manera coherente, y definitiva, 1; doctrina de nuestro filólogo, pero en Milá y Fontanals y Menén dez Pelayo hubo mucho más que atisbos ${ }^{13}$. Alfonso Reyes sabíi cuanto podía saberse; luego, coincidió en Madrid con las grande formulaciones de la escuela española y nada le resultó ajeno.

Al lado de esta literatura elaborada por el pueblo, el joven A] fonso Reyes sitúa la creación personal de Diego de San Pedro de Luis de Góngora. Si algo sorprende -y sorprende muchoes cómo aquel mozo se enfrenta con la novela sentimental. Géne ro literario que tiene su amaneramiento, como bien entendiero los mejores espíritus, digamos Cervantes o Menéndez Pelayc pero que siente vaharadas de vida en la pasión de los amante: Resulta entonces que aquellas cartas convencionales y retórica: de tradición literaria y pueriles reacciones, no eran otra cosa qu un brillante tratado de la teoría del amor, que no es fruto de $u$ azar, ni queda como desnudo airón: el viejo autor del siglo $x$ ha sabido encontrar una veta de emoción que continúa sienc nueva; no porque don Quijote la sienta, sino porque pertener a una floración que en Occidente se enlazará con las teorías c Nietzsche, bien que para rechazarlas, o con las prácticas novele cas de Flaubert, de Oscar Wilde o de Zola. Diego de San Ped. es un gran autor no sólo porque da vida a sus criaturas, sino pc que se instaura en lo que fue, y será, una forma de cultura .

\footnotetext{
1922, pp. 88-92).

12 Galdós, VI, 337.

${ }^{13}$ Manuel Alvar, "La tradicionalidad en la escuela española de filo gía", en el libro El romancero. Tradicionalidad y pervivencia, $2^{\mathrm{a}}$ ed., Barcelo1 1974, pp. 17-54.
} 
la que no nos sentimos desasidos, por más que la evolución sea constante, pero en ella identificamos un linaje, como diría Homero, y, desde él, identificamos linajes ajenos. El mozo de diecinueve años sabía mucho de la literatura sabia de su tiempo y de otros tiempos, acaso demasiado. Pero eso mismo le daba la seguridad de la interpretación y la certeza de que una obra sólo cobra sentido dentro del mundo cultural al que pertenece. Digamos que, desde las veredas de la literatura más culta, había descubierto otro sentido de la tradición. Y así cuando muchos años después quiere situar la muerte de García Lorca en un epos clásico, recurre a la tradición para evocar el pasado sin otras referencias. Y la recreación del canto del Caballero de Olmedo cumple eficazmente con su propósito:

Que de noche lo mataron

al caballero,

la gala de Granada, la flor del suelo.

En Fuentevaqueros

nació la gala:

traía cascabeles

entre las alas ${ }^{14}$.

Pero si la Cárcel de amor es un mundo deslumbrador de saberes externos, la conferencia Sobre la estética de Góngora deslumbra por los hallazgos internos del arte del gran cordobés. Estamos en enero de 1910; Alfonso Reyes tiene dieciocho años y se lanza a la increíble empresa intelectual de descubrir el mundo enmarañado que Góngora es y, desde dentro de un alma complejísima, encuentra los caminos del arte. Los hallazgos nos dejan estupefactos, porque desestimando el proceder de la crítica, se plantea una hipótesis de trabajo verdaderamente revolucionaria: su creación es paralela a la de Lope, "como un trasunto igualmente expresivo de aquella animación de la vida, de aquella fuerza sobrada, siempre dispuesta a saltar y destruir obstáculos, sólo que trasmutada a las puras faeneas del pensamiento" 15 . Pero intenta

${ }^{14}$ Cantata. En la tumba de Federico García Lorca (Obra poética, p. 135). EugeNIO FLORIT ha comentado este tradicionalismo en "La obra poética" [de A. R.] en el estudio que se incluye en el libro Alfonso Reyes: el hombre y su mundo, New York, 1956, p. 46.

${ }^{15}$ O.C., I, 62. 
explicar los modos de proceder de Góngora para que su estilo nc pudiera confundirse con el conceptismo y, sobre todo, compren diendo la pureza de su conciencia artística, que es ánimo de per fección, superación de los tópicos, elegancia expresiva, formuli Alfonso Reyes unos presupuestos de trabajo que serían funda mentales para la futura interpretación del poeta: evolución espiri tual, que no cambios de "manera"; en los poemas antiguos "st venían ya revelando las cualidades definitivas de Góngora”, po cuanto viene a probarse "cómo los defectos del Polifemo y las Sole dades son remate y término natural de las virtudes que ya desd antes empezaban a desarrollarse en el poeta, y no desviación n contradicción, sino superación, manifestaciones de una facultaı exacerbada y ya torrencial". Por si no bastara: cuanto "más s individualiza un ser, más se perfecciona en sí mismo, y más tiend a contrariar las leyes y las homogeneidades de la especie". El tra bajo no tiene desperdicio y en él estaba ya intuido el mucho sabe de las Cuestiones gongorinas $(1927)^{16}$ y, por supuesto, su trabajo co Foulché-Delbosc en dar a luz el manuscrito Chacón ${ }^{17}$. Más tard volvería sobre estos motivos y no olvidó la bibliografía más recier te; se hizo cargo de estudios de $1955^{18}$ y fue generoso con Dámc so Alonso $^{19}$. Fidelidad y devoción a unos trabajos que inició e su adolescencia y que no acabarían sino con su silencio definitive

\section{Alfonso Reyes en MADrid}

Cuando en mayo de 1949 firma el prólogo a su libro Tertulia Madrid, escribe estas nobles palabras:

Yo llegué a España dejando atrás torvos horizontes. Mis amistad españolas fueron el alivio de mis penas y me ayudaron a persis en mi verdadera vocación. Nadie me importunó con preguntas

${ }^{16}$ Pero son estudios de su época madrileña (se fechan entre 1915 1923), cf. VII, p. 7. Sobre los estudios gongorinos de Reyes hay unas págir impresionistas en el libro de James Willis Robb, Por los caminos de Alfonso 1 yes. (Estudios, segunda serie), México, 1981, pp. 56-59.

17 Véase, por ejemplo, O.C., VII, 220. La colaboración duró desde fir les de 1916 hasta 1921. También, VIII, 70.

${ }^{18}$ Había publicado reseñas bibliográficas sobre "Góngora y Améric (1929), un Boletín gongorino (1931) y en los Estudios gongorinos figuran ur "Contribuciones a la biliografía de Góngora" y una "Reseña de estud gongorinos"' (VII, 59-111).

${ }^{19}$ VII, 7. 
quiso escarbar en mis dolores; pero todos me tendieron la mano. ¿Cómo no desear para aquella tierra hospitalaria, que después he visto sufrir tanto, la felicidad y el bienestar que le prometen sus nobles tradiciones y la incomparable entereza de sus hijos?20

Sabemos la inspiración de estas líneas: muerte del padre, guerra civil española. Pero lo que ahora nos interesa es saber cuáles fueron sus amistades españolas y cómo orientó su quehacer $^{21}$.

Hemos visto cómo los estudios de nuestra literatura estaban marcados por un saber filológico y por una aguda penetración psicológica; sabemos - se ha dicho- de su "arielismo" ensayístico; consta su amor a España. La evolución de estos presupuestos le llevaría, necesariamente, a la investigación, al periodismo cultural y al conocimiento, e identificación, de los escritores y de las tierras en las que asentaba su morada. Tres puntos de apoyo que sustentan su quehacer durante diez largos años y que serán la clave de no pocas de sus interpretaciones históricas. Fundamentalmente, diríamos Centro de Estudios Históricos, Revista de Filología Española y escuela de Menéndez Pidal; diríamos, Ortega y $E l$ Sol; diríamos, gente del 98, escritores posteriores y andanzas y visiones españolas. Voy a explicar cada uno de estos motivos.

\section{El Centro de Estudios Históricos}

El mismo año de la arribada de Alfonso Reyes a Madrid, Menéndez Pidal comienza la edición de la Revista de Filología Españo$l a^{22}$. Es el momento en el que la escuela española de filología alcanza madurez, porque, junto al maestro y sus discípulos de prima hora (Américo Castro, Navarro Tomás), aparecen los de nuevas generaciones (Solalinde, Federico de Onís), la colaboración de algún gran maestro de disciplinas afines (Asín Palacios,

${ }^{20} \mathrm{VI}, 408$. La estancia madrileña está minuciosamente descrita en el libro de Barbara Bockus Aponte, Alfonso Reyes and Spain. His Dialogue with Unamuno, Valle-Inclán, Ortega y Gasset, Jiménez, and Gómez de la Serna, Austin, 1972. Debe tenerse en cuenta la "Introducción" de José Luis Martínez a la Antología general de Alfonso Reyes, Madrid, 1986, pp. 10-11.

${ }^{21}$ Para estos motivos cf el capítulo "Europa" del libro de Alicia REYES, ya citado.

22 Manuel Alvar y Pilar García Mouton, "La Revista de Filología Española", $R F, 100$ (1988), 197-203. 
García Villada, Sánchez Cantón) y el reconocimiento de los sabios extranjeros. Se inicia de este modo una andadura que, con sus altibajos, todavía persevera y en la que se descubre cuáles van a ser los campos que cultivará la naciente escuela: poesía tradicional, fonética, etimología, estudios sobre la Edad de Oro. Entre los colaboradores de los días augurales están los hispanoamericanos Pedro Henríquez Ureña ${ }^{23}$ o Francisco A. de Icaza ${ }^{24}$. Federico de Onís ${ }^{25}$ fue el introductor; el joven Reyes se incorpo. ró a las tareas y trabajó con ahínco: no rebló ante los quehaceres más modestos ni ante los más enojosos. Con Antonio G. Solalin. de redactaba la anónima, y utilísima bibliografía de cada tomo ${ }^{2 t}$ y aun, juntos, escribieron un folleto en el que animaron a lic colaboración espontánea: enseñaban a hacer fichas, adoctrina ban en la catalogación, establecían siglas ${ }^{27}$. Mucho de lo que entonces hizo fue acumulándolo como experiencias válidas y muchos años después, en diciembre de 1939, evocará aquello cinco años (1914-1919) en que trabajó en el Centro y, al saluda la aparición de la Revista de Filología Hispánica, la vio "como el ro busto brote trasplantado a tierra americana" de la revista espa ñola ${ }^{28} . \mathrm{Y}$, años después, pensaría en cómo hay cosas que se re piten ineluctablemente: también fueron motivos políticos los qu hicieron que se dispersaran los redactores de la publicación ar gentina y, en aquella fundación que don Alfonso presidión ${ }^{29}$, vi no a acogerse con la sencilla anteposición del adjetivo Nueva. Jun to a los de Amado Alonso y Raimundo Lida figuró el nombre d Reyes como fundador de la revista, a partir de $1960^{30}$, y sólo e:

${ }^{23}$ Le dedicó una hermosa "Evocación", recogida en XII, 163-171, véa: n. 120 en este trabajo. Por su parte, el maestro dominicano escribió una im: gen de don Alfonso en la que hay, también, informes biográficos que ya 1 considerado. De 1986 es la edición del importantísimo epistolario entre los di amigos; en el prólogo, verdaderamente ejemplar, de José Luis Martínez, hace la historia de estas relaciones y de la decisiva importancia que tuvo $\mathrm{He}$ : ríquez Ureña en la formación de Alfonso (Alfonso Reyes-Pedro Henríquez Ureñ Correspondencia, I, 1907-1914, ed. de José Luis Martínez, México, 1986).

${ }^{24}$ Cf. VII, 475-476 y 476-481.

25 XII, 228.

${ }^{26}$ IV, 580; IX, 180; XII, 221. A Solalinde dedicó entrañables recuerd (por ej., XII, 223-226).

27 XII, 222.

$28 \mathrm{IX}, 178$.

${ }^{29}$ La Casa de España, fundada por el presidente Cárdenas en 1939 (X] 8) (¿o en julio de 1938?), que se convirtió luego en El Colegio de México.

${ }^{30}$ Hay un emocionante recuerdo en el tomo 7 (1953) de la $N R F$; 
él duró el recuerdo de la RFE, hasta el año fatal de 1959, en que sus pasos se dirigieron al blanco muro. Pero no sólo fueron estos quehaceres los que le ocuparon: como complemento bibliográfico debemos considerar aquellas treinta y cinco reseñas que publicó en la $R F E^{31}$, comienzan en el tomo I de la revista y terminan en el X (1914-1923). Además utilizó los ficheros medievales del Centro para anotar su edición del Libro de buen amor ${ }^{32}$ y tuvo un constante estímulo en sus maestros y en sus compañeros. Años fecundos los del Centro, que no estaban limitados a la investigación (y a la convivencia), sino que - la mano de Américo Castro andaría en ello- colaboró en "un curso práctico [1918] para la preparación de profesores de lengua y literatura españolas en el extranjero", de donde redactaría las bases de unos 'Ejercicios de historia literaria española ${ }^{33}$, que reelaboraría en 1931. Junto a esto, Alfonso Reyes encontró cobijo en la RFE para publicar "Góngora y "La gloria de Niquea"" (1915), "Un tema de La vida es sueño" (1917), "Sobre Mateo Rosas de Oquendo" (idem), "Cuestiones gongorinas" (1919), etcétera.

Aquellos años del Centro debieron ser entrañables: la convivencia con los maestros estimulaba al continuo aprendizaje, pero era también una reiterada lección de humanidad. Cuando se leen los nutridos volúmenes de las Obras completas se ven aquí y allá las presencias cordiales. Un día evoca desde Río de Janeiro aquel Ventanillo toledano que, para su descanso, instalaron Américo Castro, Solalinde, Moreno Villa y él. Allí, en el callejón del Vicario, se estableció la cofradía de San Baltasar, que tantas nostalgias le suscitaba y, entonces, clave en cifra muy poco difícil, escribe:

Tal vez Américo Castro habrá dado caza a dos o tres modismos o pronunciaciones hasta hoy tenidos por andaluces, y que van resultando, puesto que se cosechan en el propio campo de Toledo, más bien popularismos o modos de hablar de toda una clase española: esto ilustra y corrige un poco lo de los "andalucismos" de Améri-

Por su parte, Alonso había escrito un valioso elogio del maestro en las Páginas sobre Alfonso Reyes, publicadas por la Universidad de Nuevo León, Monterrey, 1955. Sobre las relaciones de los dos amigos, véase James Willis RobB, Estudios sobre Alfonso Reyes, Bogotá, 1976, pp. 25-56, y, del mismo autor, Por los caminos de Alfonso Reyes, ya cit., pp. 101-113.

${ }^{31}$ Da noticia de ellas en VII, 7, y se recogieron en ese mismo volumen.

32 XII, 219

33 XII, 257-266. 
ca, rectificación a la que mucho han contribuido los trabajos de Pe. dro Henríquez Ureña ${ }^{34}$.

Sabemos que en 1924 don Américo publicó aquellos esbozo que reunió en Lengua, enseñanza y literatura; uno de ellos era, preci. samente, "El habla andaluza', y en él señalaba los arcaísmos castellanos que se conservan en Andalucía y, por ende, en Amé rica. Acaso lo que pretendían todos ellos con su antiandalucisme no pudiera confirmarse con el arcaísmo castellano: a Amérić podrían haber pasado los arcaísmos, no por castellanos de Casti lla, sino por castellanos de Andalucía. Pero en el recuerdo de Al fonso Reyes está una postura teórica que, vemos, tal vez procedi de don Américo y que Henríquez Ureña expuso largo y tendidc en la $R F E^{35}$; vendrían luego otros nombres más jóvenes forma dos o colaboradores del Centro, digamos Amado Alonso, diga mos Ángel Rosenblat. La semilla había fructificado y, tal vez, u momento pareció triunfar, pero luego Menéndez Pidal se desasic de ella ${ }^{36}$ y otros trabajos de Boyd Bowman, de Lapesa, acası hayan exigido reconsiderarla. Esto es la cuestión técnica, pero si validez no es lo que aquí veo como definitiva, sino la capacidar de la evocación cuando la vida ha dispersado a todas aquella gentes que siguen unidas por un entrañable recuerdo. Aunque también para la historia del español, no convendría echar en sac roto algo que don Alfonso escribió en Rumbos cruzados, bien poc después (1925) de irse de España:

En Sevilla, el americano siente que ha llegado a la puerta del Nue vo Mundo; que empieza América, y de Nuestra Señora del Bue Aire se parte para Buenos Aires. La visión de Sevilla era la últim norma de ciudad que los españoles llevaban en la mente. En ، hampa de Sevilla se reclutaban marineros y soldados voluntaric para las Antillas y Tierra Firme. ¡Hasta los patios y naranjos d Sevilla me recuerdan mi casa de Monterrey!37

34 II, 97. Véase, también, XI, 321-322.

35 "Observaciones sobre el español de América" (RFE, 8, 1921, 35" 390); después, El supuesto andalucismo de América, Buenos Aires, 1925. Tambié sigue a Henríquez Ureña en la división del español de América en cinco zon: lingüísticas (XI, 126).

36 "Sevilla frente a Madrid. Algunas precisiones sobre el español ( América", en Estructuralismo e Historia, La Laguna, 1962, t. 3, pp. 99-165.

37 II, 206. 
El Alfonso Reyes profesor de historia de la lengua y de la literatura españolas (1913) en la Escuela de Altos Estudios de Mé$x^{x i c o}{ }^{38}$ no debió pasar de lingüista en agraz. Ahora el recuerdo con que hilvano estas líneas procede de una evocación a don Tomás Navarro Tomás. En 1943 nuestro Reyes pronunció en México su importantísimo Discurso por la lengua y, de nuevo, rehilaba en sus emociones aquel recuerdo de los maestros del Centro. Habla don Alfonso de las reducciones americanas que son el seseo o el yeísmo; no descendamos a problemas más apurados, basta con saber que "estas formas de economía, nos decía Menéndez Pidal, tal vez representan el porvenir de la lengua [...] nuestra $j$ es más delantera que la castellana, y cuando yo llegué a Madrid por 1914 - no contaminado aún - Navarro Tomás me hacía notar que yo pronunciaba Mégico y no Méjico. Y yo me ofendía diciéndole que la profunda $j$ gutural es causa de que se oiga toser tanto en los teatros y en las iglesias madrileñas", 39 . La verdad es que no sé qué interpretaría de lo que don Tomás le dijo, pues la $j$ que yo he analizado en México ${ }^{40}$ es fricativa linguo velar, sin vibraciones uvulares, y la de Monterrey es la fricativa común en México, es decir, menos tensa y menos cerrada que en castellano, pero no aspirada. Aunque en el Atlas de México se puede comprobar que en algún informante semianalfabeto había cierta tendencia a la aspiración. Navarro Tomás no aprovechó los datos que el entusiasta alumno le brindaba y en su clásico Manual. de pronunciación nos dejó sin resolver la duda. Leemos estas notas y nos embarga una suave ternura; mil veces se repiten y otras tantas las respuestas dejan la indecisión de la cortesía. Seguimos en el Centro de Estudios Históricos; trabajan juntos - lo sabemos- Solahnde y el agudísimo mexicano que es su amigo. Discuten (la sangre no llegará al río) y Alfonso se burla del "dialecto castellano" de Antonio; Antonio "se vengaba diciéndome que yo pronunciaba Atlántico a la manera azteca". Pero "él se empeñaba en decir Ad-lántico - que no pasa de ser un feo popularismo

38 XII, 221. Pasó, en 1913, "a desempeñar la primera cátedra de filología española que hubo en México" (P. Henríquez UREÑA, Seis ensayos en busca de nuestra expresión, Buenos Aires-Madrid, 1928. Cito por la reedición de Buenos Aires, 1952, pp. 142-151. El ensayo es de 1927).

${ }^{39} \mathrm{XI}, 322$. Véase, también, II, 64.

${ }^{40}$ Por ejemplo, en "Algunas cuestiones fonéticas del español hablado en Oaxaca (México)", NRFH, 18 (1965-1966), p. 373; "Polimorfismo y otros aspectos fonéticos en el habla de Santo Tomás de Ajusco", $A L M, 6$ (1966$67), 11-42$. 
peninsular' ¿Son así las cosas? ${ }^{41}$. Y ahora, cuando yo contem plo toda esta historia acumulada sobre los grandes nombres, $m$, quedo sorprendido ante la osadía: "fue necesario acudir a la au toridad de Menéndez Pidal para que se me concediera $e$ triunfo" 42 . (Explicaba geografía lingüística en El Colegio d México. ¿Cuántas veces saldría a colación la palabra atlas? U, día, roto el muro de la desconfianza, mis alumnas mexicanas $\mathrm{s}$ me acercaron: "Maestro, diga otra vez ad-las". Nihil novum.)

Pero la anécdota fonética nos sirve para algo más: para sabe la humanidad de las figuras venerables. Alfonso Reyes lo sup gracias a su amigo Salalinde: "Yo aprendí de Solalinde una buc na costumbre, que'era resultado de su salud moral: en cuant guardábamos los papeles y salíamos a la calle, el filólogo desape recía, dejando el sitio al muchacho más sencillo que $h$ conocido"43. No sólo aquel mozo, sabemos del Ventanillo co don Américo, sabemos de una historieta digna de la lógica de $\mathrm{Pc}$ dro Saputo y los agobios que pudo producir la exquisita cortesí mexicana, no siempre bien entendida por los hirsutc carpetovetónicos $^{44}$, y sabemos de don Ramón, Solalinde y R yes angustiados en un túnel del Guadarrama, mientras el tren : acercaba $^{45}$. Que la dimensión de los grandes hombres se mic por la altura de su humanidad.

DE PERIODISMO Y OTRAS COSAS

El Madrid intelectual de Alfonso Reyes no es sólo el Centro c Estudios Históricos, es el Ateneo ${ }^{46}$, es la Editorial Calleja, sc los "Clásicos Castellanos" "47, es El Sol. Él mismo nos lo ha co] tado: Enrique Díez-Canedo le encomendó editar el teatro c Ruiz de Alarcón para "La Lectura" y ese fue el motivo de :

41 Navarro Tomás, Manual de pronunciación española, $21^{a}$ ed., C.S.I.C Madrid, 1982, § 131, pp. 142-143. ¿Lo que el fonetista dijo sería que la jc de. Reyes era algo más adelantada que la madrileña?

42 XII, 224.

43 XII, 223.

${ }^{44} \mathrm{IV}, 395-397$.

${ }^{45}$ IV , 394; XII, 219

46 Véase, por ejemplo, V, 345. Colaboró con Azaña cuando éste era ؛ cretario de la casa y aun gozó de su confianza, pues le encargó la Sección Li raria (II, 41). Con él colaboró también en La Pluma (II, 42).

47 En ellos publicó, con el núm. 37, La verdad sospechosa y Las paredes o. (1923). 
aproximación a Menéndez Pidal ${ }^{48}$. Algo después (1917), Calleja le encargó los clásicos populares que comenzaba a editar ${ }^{49}$ : Juan Ramón Jiménez había pasado a ser, desde 1915, el inspirador artístico de la casa y su nombre habrá que unirlo al de Alfonso Reyes $^{50}$. En la nueva colección - una de las pocas cosas que se lograron en los ambiciosos proyectos - vieron la luz las Páginas escogidas de Quevedo (1917), el Libro de buen amor (id.), las Páginas escogidas de Ruiz de Alarcón (1918), los Tratados de Gracián (id.), el Teatro de Lope de Vega (1919) y en Calleja publicó su Ifigenia cruel (1924).

Pero lo que realmente marcó su actividad madrileña fueron sus colaboraciones en El Sol. Nos lo ha contado muchos años después, en el "Prólogo" al tomo $\mathrm{V}$ de sus Obras completas, firmado en 1952:

. . tuve a mi cargo durante algún tiempo una página de geografía e historia que aparecía todos los jueves en El Sol de Madrid. Cuando José Ortega y Gasset -inspirador del periódico- me hizo el honor de invitarme junto a otros amigos, para que entre todos nos distribuyéramos semanariamente las distintas ramas del estudio y la información - la economía, la educación, la medicina, las artes, etc.-, yo no vacilé en aceptar, porque, me dije, cuanto acontece en el tiempo es historia, y en el espacio, geografía ${ }^{51}$.

La teoría es así, pero, en su realización, Alfonso Reyes actuó como un español preocupado por los temas de España. Sorprende su interés por cuestiones insólitas, que sólo nos afectan a nosotros y cuyo valor, incluso, podía ser ocasional. Bastaría leer Entre libros $^{52}$ para que nuestro estupor no saliera de asombro: el archivo ducal de Osuna, la reforma de la historia del arte, la crónica de Alfonso III, el emplazamiento de Bílbilis, las conchas marinas y las emigraciones, Martos y los Carvajales, un rector de doce años, España y Gibraltar, excavaciones en Ibiza y en Lérida, Portugal y Colombia, la misa de Luis XVI, la esperanza china,

${ }^{48}$ II, 42; XII, 221.

49 XII, 220.

50 II, 42. Véase APONTE, op. cit., pp. 122-153. El retrato que le hizo JUAN RAMón (1933), aparte de muy bello, es sagacísimo (Españoles de tres mundos, Madrid, 1960, pp. 180-182).

$51 \mathrm{~V}, 11$. Ortega lo llevó también al semanario España y después a $E l$ Imparcial (II, 42). Las colaboraciones en $E l$ Sol fueron posteriores. Cf. APONTE, op. cit., pp. 91-121.

52 VII, a partir de la p. 251. 
la historia de Mesopotamia, etc. Aparte, claro está, las valoraciones literarias, que esperaríamos, y que no merece la pena traer a colación, pues son tantas. Si los temas de la actualidad más candente lo asoman a la política actual o a la historia, otros españoles hacen que sus líneas cobren no escasa actualidad: en un ar. tículo de 1918 aclara algunos extremos en una discusión sobre Cisneros. Alfonso Reyes ve en el Cardenal el absurdo enfrenta. miento de las dos Españas. En los Retratos ideales $e$ imaginario. (México, 1920), había una semblanza de Cisneros que recogíc valoraciones encontradas ${ }^{53}$, y daba su visión, precisa, del grar personaje. Justamente a él, y la estúpida polémica, había de de dicar unas líneas - de nuevo la ponderación- en $1952^{54}$ :

Yo, en mi corta experiencia, quise alguna vez resumir las opinio nes de la prensa española cuando el cuarto centenario del Cardena Cisneros: me encontré con que unos pedían el advenimiento d otro varón de igual temple y la chamusquina de sus adversarios po líticos -credo que muchos profesan y pocos confiesan-, al pas que otros le negaban todo al reorganizador religioso, corregidor d la nobleza, conquistador de Orán, fundador de la Universida de Alcalá y mecenas de la Políglota Complutense.

Un día, un joven doctor nuestro se presentaba en la Editor Nacional: había traducido la vida de Gisneros escrita por Alva Gómez de Castro; pretendía, vana ilusión, que se la publicarar Está ya en alemán y en francés, pero no en español. El archipárr pano de turno respondió con ecuanimidad: "Cisneros no intere sa'. Toda exégesis eludo.

Don Alfonso no estaba por las dicotomías y sus ensayos so un espléndido testimonio de integración, incluso en cosas qu suelen discutirse hasta el aburrimiento. En El Sol publicó artícr los como El sentido de la política ${ }^{55}$ que bien valen como paradį̧ ma ${ }^{56}$. Y, si necesario fuera, recordaría el Viaje a la España de Ca trogil: "Mala nueva para los augures de catástrofes: España esı toda viva, entera, bajo la piedad del cielo que la protege",57.

${ }^{53} \mathrm{El}$ artículo es de 1918 o anterior, porque en él hay especies que lue! figuran en la apostilla que acabo de aducir.

${ }^{54}$ Prólogo al t. V de sus $O . C$. , p. 12.

${ }^{55}$ III, $357-360$.

${ }^{56}$ Léanse las extraodinarias palabras que dio a la BBC de Londres, tit ladas "Algo sobre Castilla" (IX, 329-330).

57 II, 189. 
Alfonso Reyes, a través de la prensa, se incorporó también a la vida de España; quedan los comentarios sobre nuestra políti$\mathrm{ca}^{58}$, sobre motivos tan remotos como nuestros derechos al patronato de los Santos Lugares ${ }^{59}$, sobre nuestra conducta en Guinea $^{60}$, sobre los libros o el teatro que apasionaban en sus días. Digamos una inacabable teoría de saberes y de identificaciones. Alberto Gerchunoff, en el Prólogo que puso a la edición chilena de Aquellos días (1938), dice: "En la época en que Alfonso Reyes vivía en Madrid, se dedicaba casi exclusivamente a la literatura desinteresada y al periodismo activo"61. Quedémonos con las últimas palabras. Periodismo activo fue para él entender la historia, acercarse a los hombres que la hacían y trascender los hechos para situarlos en relación con el pasado. Pienso que todo era lo que Ortega venía practicando y que Alfonso Reyes aprendió muy bien. Decir imitación es una mezquindad que, entre otras cosas, habría que probar y que, tal vez, no dijera nada. Pienso en el talante afín de los dos escritores que les llevó a entender del mismo modo una común tarea. Acaso pesaba sobre ellos una gran tradición inglesa que, desde las columnas del periódico, hizo surgir la elaboración del ensayo. Pienso en muchos artículos de Alfonso Reyes, increíbles como publicación periodística, como pienso en los ensayos de Ortega nacidos en las hojas volanderas de los diarios, pero creo que nuestro filósofo tenía razón cuando, al grabar para El Archivo de la Palabra, decía que al español hay que hablarle allá donde puede escuchar: en la tertulia del café o en las columnas de los diarios. Esto hizo también Alfonso Reyes y esto hizo, acaso, que el joven Ortega se fijara en aquel joven mexicano que necesitaba ayuda, y se la dio en España, en El Imparcial, en El Sol, porque previamente habían coincidido en el espíritu.

\section{ESCRITORES ESPAÑOLES}

Cuando leemos los primeros tomos de las Obras completas pensamos aquí Azorín, aquí Ortega, aquí Gómez de la Serna. Pero al adentrarnos en el tomo III, la suposición se convierte en certeza.

\footnotetext{
${ }^{58}$ III, 331-336.

${ }^{59} \mathrm{IV}, 143$.

${ }^{60}$ IV, 36-42.

${ }^{61}$ III, 307.
} 
En un momento de las Nuevas dilucidaciones casuisticas escribe "Mucho lamentaría calumniar a los hijos de su espíritu [de $A z o$ rín] en este aprovechamiento simbólico que suelo hacer di ellos"62. Y es que Azorín fue su "primer amigo de España", : quien conoció al llegar a San Sebastián y con el que la amistac se acreció: cuando nuestro escritor fue subsecretario de Instruc ción Pública lo llevó a Burdeos para asistir a las fiestas del armis ticio: Reyes buscó Goya y Marchena y fray Servando Teresa d Mier ${ }^{63}$. En Azorín encontró su visión de Castilla que vino a se su identificación con España: llegaremos así a las dos estremece doras páginas que escribió para la $\mathrm{BBC}$ de Londres cuando $\mathrm{s}$ cumplía el milenario del condado, páginas de amor, de re quiebro, de pasión sin fronteras. Pensaríamos en la España clara tan tardía, y pensaríamos en aquella lección que nos dieron a lc españoles los hombres del 98:

Castilla no se presta a interpretaciones sutiles ni paradójicas. Ca: tilla tiene algo de evidencia, de cosa fundamental, de principio in conmovible. La aceptamos, casi, como una gravitación fatal de historia [...] Castilla es cimiento, semilla, tradición, centro, ne vio, alma. Castilla es valor, sobriedad, aceptación realista a la vt que liberación metafísica. Es virilidad, pobreza con limpiez: alegría prudente y sin estruendo, virtud sin teatralidad, poesía s: extremos de artificio, justicia no exenta de piedad, heroicidad $c$ llada y bondad. [...] Castilla es la España sin anécdota [...] I la España de piedra y cielo ${ }^{64}$.

¿Sabríamos nosotros añadir una palabra?

Azoriniana es la valoración del español ${ }^{65}$, su capacidad pa: adentrarse en la sociedad y captar la atmósfera que la cerca o 1 . preferencias mentales agazapadas en lo más recóndito del hor

${ }^{62}$ III, 263. Sorprendentemente, Aponte no dedica ningún capítulo a relaciones de Reyes con Azorín. En 1956, don Alfonso cita a Azorin (juntc Menéndez Pidal, Henríquez Ureña, Díez-Canedo y Borges) entre los ma tros con los que tiene deudas (cf. J. L. Martínez, op. cit. en la n. 23, p. 1 ${ }^{63} \mathrm{II}, 43$.

${ }^{64}$ IX, 329-330. Cuando Reyes vivía en Madrid, Pedro Henríquez U ña publicó en México el libro Mi España, ya citado, donde incluye un estur sobre el gran prosista.

65 "Del pueblo proceden todas las cosas buenas de España" (III, 33 Para todo esto, véase Pedro Laín Entralgo, La generación del 98, Madr 1947. 
bre ${ }^{66}$, ese descubrir el pulso de los libros ${ }^{67}$, el valor de la tradición, previo a cualquier intento revolucionario ${ }^{68}$, el comedimiento ante la política ${ }^{69} \mathrm{y}$, tantas veces, el estilo vivaz, impresionista y sintético del autor de La voluntad. No es deuda escasa, pero Alfonso Reyes jamás fue cicatero en sus gratitudes.

Creo que ni el Valle-Inclán de los Cartones de Madrid ${ }^{70}$, ni el de las Divinas palabras, tan sagazmente estudiadas ${ }^{71}$, ni el del americanismo sentido y profundo ${ }^{72}$; ni el Baroja admirado ${ }^{73}$, ni el Unamuno con el que tantas afinidades pudo tener ${ }^{74}$, ninguno de ellos significó nada comparable. Porque una cosa es la admiración y otra la devoción. ¿Cabe elogio mayor del que hace de Galdós ${ }^{75}$ ? Y no podemos decir que lo condicionara en su quehacer. Nos quedamos con el magisterio de Azorín y, luego, con la amistad de los escritores llamados novecentistas: digamos $\mathrm{Ra}^{-}$ món, Juan Ramón, Ortega. Los ensayos que les dedica son sagaces. En Gómez de la Serna ${ }^{76}$ ve cuanto de externo podía encontrarse en su torre o en Pombo, su fecundidad y sus caprichos, su rebeldía y su trascendencia, su universalidad y su madrileñismo; todo cierto, pero la exactitud del diagnóstico está en descubrir lo que el escritor tiene de escritor; es decir, cuanto pertenece a la esencia de su arte y no a la anécdota ajena al quehacer literario. Entonces escribe: "la lealtad de las palabras le ha impuesto un estilo, un corte de frase y una adjetivación muy suyos. No es que él haya acabado por ajustarse al lenguaje, sino que el lenguaje, a tanto insistir, ha abierto una brecha por su espíritu, penetra por él como un golpe de viento, y se roba sobre sus cien alas todo

${ }^{66}$ IV, 21.

${ }^{67} \mathrm{IV}, 247$.

${ }^{68} \mathrm{IV}, 256$.

${ }^{69} \mathrm{IV}, 403-404$.

${ }^{70} \mathrm{Se}$ incluyen en el t. II de las O.C. Véase, además, Aponte, op. cit., pp. 63-92.

${ }^{71}$ IV, 100-105. Véase también, las pp. 405-406 del mismo volumen.

${ }^{72}$ IV , 283, passim. También Henrí Quez se ocupó del asunto (Obra crítica, México-Buenos Aires, 1950, p. 683).

${ }^{73}$ IV, 122.

${ }^{74}$ IV, 177, 279, 390. Gabriela Mistral habló de la "tortura unamunesca"' de Reyes (cit. por IdUARTE, op. cit., p. 9). Cf. Aponte, op. cit., pp. 29-62.

75 "El mayor novelista de la lengua en el siglo XIx, y uno de los mayores en todos los tiempos y literaturas" (VI, 332).

${ }^{76}$ Ramón Gómez de la Serna (IV, 183-191). Véase AponTe, op. cit., pp. 154-183. 
lo que puede"'77. De ahí ya la interpretación de la vida comc una constelación de greguerías o el retrato, justo, perfecto, de aquel hombre para quien las casillas de la clasificación todavíi no se han inventado: "Ramón: Hijo de tu pueblo, golfo intelec tual de la Villa y Corte: bajo la gorra sospechosa de tu ironía te veo escabullirte, saltando sobre el Carolus de la calle empedra da, con la navaja de escribir en la mano. Solo tú sabes por dónd se está desangrando, gota a gota, el corazón de Madrid''78.

Sabemos de la amistad de Alfonso Reyes con Juan Ramó Jiméne $z^{79}$ y aun habría que añadir su colaboración en Índice, 1 revista del poeta de Moguer $^{80}$. No es bastante: están tambié: los Apuntes en los que bellísimamente retrata al creador o narra con piedad, sus manías ${ }^{81}$. La silueta es sagaz y está trazada co firmeza. Es un buen retrato literario. Haría pensar en los de Gí mez de la Serna o en los del propio Juan Ramón. En torno : poeta, la evocación de los antiguos que, con certeza, le hubiera agregado: Góngora, Goethe. Y la pasión por depurar una obr que nunca se estima perfecta.

El otro amigo de la generación fue Ortega. El filósofo fue $n$ ble - es adjetivo de Reyes - con el visitante. Le abrió puerta: Le dio el prestigio de su amistad. Don Alfonso no lo olvidó y, hemos visto, su periodismo resulta orteguiano, orteguiana ‘ - avant la lettre - su conciencia de la misión que debe tener Universidad $^{82}$ : frente a su carácter de máquina burocrátir -de nuevo hemos vuelto al mismo malacate, o a otro peor aúnAlfonso Reyes contempla la autonomía universitaria de 1919 la ve remedo de la alemana, sin la educación individual y soci que entonces tenían las norteamericanas. Ahora tendría que vc ver a repetir amargas consideraciones: se ha tomado lo malo c Estados Unidos y no podemos hacernos cargo de sus muchas vi tudes. Alfonso Reyes sabía muy bien lo que debía hacerse, y que sabían los mejores espíritus de 1919, lo que ocurre es que e tonces (ni hoy) no les quisieron hacer caso. Seguimos con las $\mathrm{m}$

${ }^{77} \mathrm{IV}, 188$.

${ }^{78} \mathrm{IV}, 191$.

${ }^{79}$ Véase supra.

${ }^{80}$ II, 42.

${ }^{81} \mathrm{IV}, 270-275$.

${ }^{82}$ La crisis de la Universidad española (III, 351-356). Al tema de la Univ sidad volvió Alfonso Reyes en La hispanización (1946); en este ensayo tra ba de la institución colonial, pero sus consideraciones no tienen limitacios (XII, 305). 
mas penurias bibliográficas, con la mala organización interna, de espaldas a una sociedad que no colabora con ella (y acaso si colaborara, no faltaría el intrusismo). Entonces, como hoy, Alfonso Reyes ha puesto el dedo en la llaga: "los renovadores de España son algo impacientes: no quieren corregir las cosas, preferirían hacerlas de nuevo"83. Es una prolusión sobre España, como las de Ortega en Vieja y nueva política (1914), en las Meditaciones del Quijote (1914). El pensador se amarga por la desesperanza y funda la revista España (1915). Invita a Alfonso Reyes y empieza la colaboración; tal vez el viaje de Ortega a la Argentina abra las compuertas del total entendimiento: el filósofo tiene la trágica inquietud de Fausto y el hombre que viene de la América de la tristeza ha descubierto el camino de las sonrisas. Juntos ahora, los dos, con la esperanza de la alegría ${ }^{84}$.

La literatura con la que Alfonso Reyes convive es de una esplendorosa brillantez. Aquella España, culturalmente, vivía un singular momento y él no fue ajeno a nada de lo que sus ojos veían. Acertó a estar en los mejores sitios y a colaborar con los mejores. No es mala recomendación. Entonces cobró cabal sentido aquel mundo deslumbrador que traía muy bien aprendido: repetir lo que evoca de la Edad Media sería, casi, escribir un tratado, pero ¿cómo olvidar su versión del Cid, que hemos leído todos los niños españoles ${ }^{85}$ ? ¿y su versión poética de los fragmentos de Santa María Egipciaca ${ }^{86}$ ? ¿y su pasión por Gracián ${ }^{87 ? ~ ¿ y ~}$ su devoción por Quevedo ${ }^{88}$ ? Por no repetir cosas que ya he dicho o que harían interminable la nómina. La estancia en Madrid había cerrado el ciclo de una literatura esplendorosa cuyo primer deslumbramiento estaba en los libros. Ahora, sí, los libros, con los sabios que les devolvían la vida, o con los autores que los creaban, o con los artesanos que les daban forma perdurable. Era la visión de España que, intuida sólo, ahora había cobrado cuerpo. Pero no era todo. Alfonso Reyes tenía que descubrir también el paisaje que sustentó a los hombres.

${ }^{83}$ III, 356.

${ }^{84} \mathrm{IV}, 265$. Sobre los ensayos de Reyes, cf. James Willis RobB, El estilo de Alfonso Reyes. Imagen y estructura, México, 1965.

${ }^{85}$ La primera edición es de 1919.

${ }^{86}$ II, 104-106, 188-189. Manuel Alvar, Tres retratos de María Egipciaca interpretados por Alfonso Reyes (en prensa).

${ }^{87}$ II, 67, 257, 458; VI, 136.

${ }^{88}$ VI, 74; la fantasía "Los huesos de Quevedo", que se incluye en $E l$ cazador. 


\section{LAS TIERRAS DE EsPAÑA}

Todas estas obras y los hombres que las crearon, todos estos seres de excepción y los millones que verbenearon hasta ser humus anónimo, vivieron sobre un suelo, vieron unos paisajes, habitaron unos pueblos. Ahora Alfonso Reyes ya no tiene un conocimiento libresco, sino que está inmerso en una realidad que lc cerca y a la que busca sentido: "Los hispanoamericanos de mi edad creen todos, ya, en España. Antes de venir aquí, yo creía - con restricciones, naturalmente- en ciertas grandezas del pa. sado español y en la fecundidad actual de ese pasado, en la fecun. didad posible. Ahora, que estoy aquí, creo en su presente y er su porvenir"'89.

Nos parece un fragmento de Azorín, hasta el título podría se: prestado ( $U n$ campesino andaluz); lo importante es esa postura cor la que quiere amar a España. Leyéndolo, uno recuerda el vers estremecido de Turoldus, "claire Espaigne la belle", justament lo que no era - ya- noventayochismo, lo que vino a negar a $l_{\text {i }}$ España negra de Verhaeren y Regoyos. Alfonso Reyes sabía d este libro y lo aproximaba a Goya; ciertas las coincidencias, per no en el humor de los negros inclementes.

Goya da a Reyes una clave de la interpretación de España La España trágica, que existe, y a la que el mexicano querí identificar con la propia tragedia de su pueblo. Pero hay otro Gc ya, el de las inverosímiles transparencias, el de la ternura má delicada, el de las emociones temblorosas. Todos hemos vist unos y otros cuadros y, sin darnos cuenta, hemos preferido 1 que en un momento mejor cuadraba a nuestro estado de ánim (los cartones o las pinturas negras y los niños, las mujeres de ca: nes turgentes o las delicadas transparencias). Alfonso Reyes tan bién; más aún, en Burdeos busca a Goya y nos deja una estamp inolvidable: "Goya pintaba mucho, sin corregir lo que pintab: Pintaba alguna vez sus recuerdos: los toros de España, las muj res de España; y, sobre todo, parecía evocar aquel paradigma c manolas, aquella hermosa figura que se le había quedado con en las manos, en el hábito de reproducirla una y otra vez: la D quesa de Alba"90. Alfonso Reyes, como el gran aragonés, 1 era un desterrado, sino un emigrante y sentía las nostalgias q' lo devolverían a México en 1959. Entonces ve en Goya su prop

$$
\begin{aligned}
& { }^{89} \text { II, } 156 . \\
& { }^{90} \text { II, } 238 .
\end{aligned}
$$


imagen y la identifica en lo que es, compleja y contradictoria, sintiendo los halagos de los grandes para volverles la espalda en busca de las aberraciones o las gentes desdichadas ${ }^{91}$. Negror de Goya que es el México desheredado, como el que describe por el arte de Diego Rivera, redactado con palabras que pudieran pertenecer al hombre de Fuendetodos: "El muerde, al pintar, la materia misma; y a veces, por amarla tanto, la incrusta en la masa de sus colores, como aquellos primitivos catalanes y aragoneses que ponían metal en sus figuras. Pintar así es, más bien, desentrañar la plástica del mundo, hundirse en las fuerzas de la forma ${ }^{92}$, acaso intentar una nueva solución al problema del conocimiento" "93. En el fondo, el hombre que en Madrid vivía su pasión de España estaba elaborando su teoría de amor a México. En 1919, escribe La reforma moral, tema bien noventayochista, y Reyes - naturalmente - lo sabe. Los nombres van llegando a los gavilanes de su pluma: Diego Ruiz, Ortega, Salaverría, Unamuno. Pero lo que está haciendo escribir esas escuetas páginas son los latidos del corazón:

Tarde o temprano, todos los pueblos se entregan a una discusión semejante. Y un día la hemos de ver en México: cuando - como decía uno de los nuestros- «algunos se decidan a emprender la reforma moral». ¿La reforma moral? Sin duda: cada medio siglo, o quizá menos, la conciencia de los pueblos la ensaya por instinto; y sólo la ataca de veras muy de tarde en $\operatorname{tarde}^{94}$.

Pero la España que Alfonso Reyes ve es la España de Azorín. Encuentro sintomático que no pareció interesarse por Zuloaga ni por Solana. Su inclinación buscaba otros rumbos: entre 1914 y mediados de 1917 escribe los opúsculos que pasaron - muy tar-

91 “ ¿No habremos de creer que Madrid es hijo de Goya? ¿De dónde pudieron salir esos mancos y cojos, ciegos, bizcos, tuertos, gigantes, enanos, mudos, corcovados y patizambos?" (II, 68). Digamos, ¿y el Velázquez que descomponía la materia en transparencias argentadas o carmesíes? ¿Y los bufones, los locos, el bobo de Coria? ¿Y el aire sutil de Madrid?

${ }^{92}$ Citemos, por lo mucho que vale, aquella carta de Goya en que habla de los maestros que enseñan pintura a su protegida María del Rosario: "esos maestros amanerados que siempre ven líneas y jamás cuerpos. Pero ¿dónde encuentran líneas en la naturaleza? Yo no distingo más que cuerpos luminosos y cuerpos obscuros, planos que avanzan y planos que se alejan, relieves y concavidades" (II, 238).

93 II, 66.

94 III, 342. 
de- a Las vísperas de España (1937) ${ }^{95}$. De ellos habría que desti car los Cartones de Madrid, Las Horas de Burgos (y compararlas co la España negra de Verhaeren y Regoyos), La saeta y visiones y ar danzas de otros folletos. Estos cuadros (¿evocan los cartones gi yescos?) tienen su mucho de visión de una realidad teratológic (viejos, pícaros, monstruos), de estampas costumbristas (el er tierro de la sardina), de cultura actual (la Residencia de Estt diantes) o de retratos literarios (Mesonero, Valle-Inclán, Ginı de los Ríos). No es necesario denunciar antecedentes, pues 1 , tiene en la mente cualquier lector, lo que me interesa es señal: cómo Alfonso Reyes intenta entender las cosas confiando en que han visto los espíritus egregios ${ }^{96}$, la mezcla de la realid con las creaciones literarias del pasado ${ }^{97}$, los hechos insigni cantes de que se urde la vida de cada uno sin que podamos ev dirnos de la emoción ${ }^{98}$, la admiración por las gentes sencilla hospitalarias, corteses y dueñas de una lengua admirable ${ }^{99}$, etc etc. Y desde estos "primores de lo vulgar" adivinar el sentido ، la historia.

\section{ESPAÑA Y AMÉRICA}

Tarde ya (1941), Alfonso Reyes escribe el Significado y actualia de "Virgin Spain". El largo ensayo que dedica a la obra de Wal Frank, es inútil decirlo, está lleno de sagacidad, pero hay en una escueta frase ("España es el camino para nuestra Amé

95 II, 36.

96 Cf.: "En España, la moral y la mística se amansan y se vuelven ca ras. Libro representativo es La perfecta casada de Fr. Luis de León; y tamb el de Ramón y Cajal sobre los métodos de la investigación biológica, dor los consejos casi técnicos alternan con los paternales, y tras de hablar de ley científica se habla de la elección de mujer [ . . ] Baroja opina que esta mia de ideas morales es producto de las mesetas" (II, 65).

97 Baste leer La prueba platónica (II, 78-80). En algún momento lo c con acertada precisión: "Azorín no es un novelista a la manera convencior no crea hombres [...] Crea nombres; mejor: recuerda nombres (Calisto, I libea, Tomás Rueda, la Ilustre Fregona, etc.); y, con pretexto de tales nc bres, nos describe una sola alma: la suya. $\mathrm{Y}$ no directamente, ni por me de la pasión o la acción, sino de la contemplación: el rasgo del paisaje, el e do de ánimo"' (II, 246).

98 Véase El curioso parlante (II, 81-83)

99 Burgos, en II, 111. O la bellísima estampa de El castillo (II, 117-11 
ca" ${ }^{\prime 100}$ ) que viene a culminar cuanto de un modo u otro hemos considerado hasta ahora, porque ello no es sino el conciso enunciado de lo que Alfonso Reyes entendía por la historia del continente y sabía muy bien que tal obra no hubiera podido hacerse sin España: "La fábrica actual de nuestra América se levantó en medio siglo - de 1492 a 1542, más o menos- y conviene recordar como sus obreros principales a Colón, Núñez de Balboa, Cortés ${ }^{101}$, Magallanes y Pizarro"102. Desde estos presupuestos su postura no admite ambigüedades; él, mexicano sin tacha, veía por eso mismo las cosas en lo que tienen de trascendente y no en valoraciones superficiales. Al decir que "la hispanización fue fecunda. No ahogó la índole nacional; no estorbó la precoz manifestación de la idiosincrasia mexicana en la nueva lengua"103, está pensando en el proceso de integración cultural que, como el biológico, fue resultado de un mestizaje que era integrador ${ }^{104}$. Y esto quedó bien patente en su abarcador ensayo al que tituló "Notas sobre la inteligencia americana", incluido en la Última Tule (1942). Diríamos que están en la línea de la raza solar de Vasconcelos o en la plenitud de España de Henríquez Ureña. Es lo que, desde una perspectiva estrictamente científica, han establecido sabios como don Ángel Rosenblat ${ }^{105}$; no sería muy distinto lo que este investigador infiere, tras infinidad de argumentos bien probados, de unas palabras que Alfonso Reyes pone como culminación de un hermoso fragmento que dedica al mestizaje: "La laboriosa entraña de América va poco a poco mezclando esta sustancia heterogénea, y hoy por hoy, existe ya una humanidad americana característica, existe un espíritu americano"'106. Cierto que llegar a esta ponderación ha exigido limar

100 XI, 139. Las visiones de España y México en la obra de Reyes son tratadas de manera muy restringida por APONTE (pp. 183-195).

101 Véase la defensa del escritor Cortés contra el juicio de Gracián (II, 471). Y ahora el libro deslumbrador de José Luis Martínez (Hernán Cortés, México, 1990).

102 IV, 154.

103 XII, 310.

104 "He aquí una vez más y siempre, la espléndida integración hispánica, el ser total que se expresa a través de todos los estilos y las maneras, quebrando los moldes convencionales y canónicos donde no ha cabido nunca la ancha respiración española" (VI, 3,33). Son palabras que refirió a Galdós, pero que son las que dan validez a cuanto considera de América, según vamos a ir viendo en el texto.

${ }^{105}$ La pablación indígena y el mestizaje en América, 2 ts., Buenos Aires, 1954.

106 XI, 83. Véase Pedro Henríquez Ureña, La utopía de América, ensayo 
asperezas y dejar obrar al tiempo; sin ello, los prejuicios no ha rían sino impedir el entendimiento, que es una forma de no se libres. Frente a la desespañolización del argentino Sarmiento o de mexicano Ramírez, la madurez del pensar, que no la rebeldía d la adolescencia, permitirá a los americanos "amar a España si compromisos, sin explicaciones y sin protestas. La hora en qu sintiéndose otro, el hombre se sienta semejante a sus familiare y como justificado en ellos"'107. También los españoles tuviero que aportar las mismas dosis de comprensión y aceptar que era propias las glorias de América ${ }^{108}$. Que todo esto había que d' cirlo es evidente, como también lo es que debieron olvidarse pi ternalismos e incomprensiones. Si en América fue don Andri Bello quien rompió lanzas por la unidad, Menéndez Pelayo Unamuno le secundaron en sus esfuezos, y si Alfonso Reyes Henríquez Ureña se convirtieron en paladines, paladines fuerc Valle-Inclán y Ortega ${ }^{109}$. Dejemos las cosas en un punto que : es historia ${ }^{110}$. Fijémonos en una realidad: la cultura son es bienes compartidos que a todos nos corresponden por igual y qr obligación nuestra - de unos y de otros- es conservarlos y acr cerlos, porque es "el repertorio del hombre", su esencia y co servación ${ }^{111}$; pertenecer a una cultura es compartirla y comur carla, pero mal pueden lograrse los frutos si desde un princir no hay una "verdadera simpatía moral" que lleva a la fusión el mestizaje sea cultural o biológico, en hacer de la vida u "sangría abierta y generosa" "112 o lo que había de decir a Wal

varias veces reimpreso y que cito por Plenitudi de América, Buenos Aires, 19 pp. 11-19.

107 Los escribió al inaugurarse en Madrid la glorieta de Rubén Dé (Los dos caminos, O.C., IV, 319). Conviene leer la continuación del texto c he transcrito y el bello ensayo de Henríguez Ureña, Raza y cultura hispán en la obra citada en la n. anterior, pp. 50-51.

108 IV, 318.

109 Reyes exhortaría a la americanización de Azorín o de Baroja ( 254, 342-343).

${ }^{110}$ Quiero que sea válida para siempre esta afirmación: "Hace tier que entre España y nosotros existe un sentimiento de nivelación y de ig dad" (XI, 90).

111 "Para inaugurar los Cuadernos americanos" (XI, 150).

$112 \mathrm{XI}, 84-85$. Copio un fragmento, muy corto para lo que vale en "Ya los primeros mentores de nuestra América, los misioneros, corderos de razón de león, gente de terrible independencia, abrazaban con amor a los dios, prometiéndoles el mismo cielo que a ellos les era prometido. Ya los pri ros conquistadores fundaban la igualdad en sus arrebatos de mestizaje". 
Frank: "España ya no es un fragmento de tierra, sino un jirón de alma humana [...] Insistir en las reservas de sonrisa y gravedad, de virilidad y de gracia, que nuestra España guarda todavía como tónico y bálsamo para los estragos del mundo, es atravesar con un rayo de sol la cerrazón de los horizontes actuales""113. Alfonso Reyes no se cansa de entonar su credo. Sus páginas son una honrosa lección para las gentes de América y obligan a una gratitud honda a las de España, forzadas por su generosidad a tener una responsabilidad histórica de la que jamás debiera abdicarse. América es nuestra llamada y nuestro porvenir: por América, España no será nunca una parcela de Europa que se agota en sí misma o que, trasplantándose, es incapaz de crear nuevas formas de cultura. La esencia misma de lo ibérico es su universalidad; por eso no podrá prescindirse de él sin "una espantosa mutilación", pues — son palabras de don Alfonso- "lo ibérico es una representación del mundo y del hombre, una estimación de la vida y de la muerte fatigosamente elaboradas por el pueblo más fecundo de que queda noticia. Tal es nuestra magna herencia ibérica"114. Alfonso Reyes ha reescrito la Salutación del optimista. Sus palabras están llenas de fe y esperanza, pero no por un acto de adivinación poética, sino por la sabiduría que da el asiduo contacto con los libros, la meditación sobre la historia y el conocimiento de los hombres. Entonces escribe, como Henríquez Ureña, esa otra lección de la Hispanidad, en la que no caben los vacuos gorgoritos ni las irresponsables falacias. Es la postura del sabio que, sin renunciar a lo que le es propio, puede hacer suyo, por una asunción platónica, lo que recibe por herencia. Sabe muy bien Alfonso Reyes que su cantar del Gid, su Juan Ruiz, su San Juan de la Cruz o su Lope de Vega le pertenecen con tanta licitud como su Rosas de Oquendo, su Ruiz de Alarcón o su Sor Juana Inés de la Cruz. Sabe también que el mundo no es una organización maniquea, porque el mal y el bien andan entreverados en el corazón de los hombres ${ }^{15}$, que las raposas co-

113 XI, 149. El subrayado es mío. También emplea el posesivo en la p. 141 del mismo tratado. Waldo Frank colaboró en el Libro jubilar de Alfonso Reyes (México, 1956) con su ensayo "The Meanings of Alfonso Reyes". Pedro Henríquez Ureña escribiría un libro al que puso el transparente título de Mi España.

114 XI, 152. Cfi. Henríquez Ureña, op. cit. en n. 107, p. 51.

115 "Los aztecas, raza militar, dominaban por el terror a un conjunto de pueblos heterogéneos, y sólo escapaban a su imperio los muy alejados o los muy bravos, como la altiva república de Tlaxcala, cuyos hijos preferían coci- 
men mejor en los campos abiertos que en las factorías mercanti$\operatorname{les}^{116}$ y que la independencia de América estaba ya en el corazón de los primeros colonizadores ${ }^{117}$. No se trata de hacer leyendas negras o blancas, tan sin sentido unas como otras, sino de entender la historia irreversible de América y entonces -en sus conversaciones con Waldo Frank - encuentra algo que no puede silenciarse: la lengua ha establecido una unión de la que no puede zafarse la creación literaria118 y con ella "el sentido hispano de la vida, hasta hoy jamás derrotado, sino lanzado siempre a nuevos rumbos en busca de otras aventuras"119. (Rubén volvería a asentir desde sus sombras ${ }^{120}$.)

FINAL

Alfonso Reyes vino a España en unas condiciones personalmente dramáticas. Aquí encontró la paz que buscaba y la discreción de las gentes que lo trataron. Cosas que supo valorar, pero, además su quehacer literario se enriqueció hasta límites insospechados Estaban, sí, sus condiciones de hombre excepcional, y sin ella: todo lo demás sería agua de pie; no hay que olvidar — sin embar go- que aquí encontró un mundo cultural difícilmente compa rable a ningún otro, que, por si no bastara con ello, le abrió su: puertas con increíble generosidad. Aquellas gentes de "la segun da edad de oro" fueron con él lealísimos compañeros y tuvo

nar sus alimentos sin sal a tener trato con los tiranos de Anáhuac. Los azteca vivían sobre los despojos de civilizaciones vetustas y misteriosas, cuya tradi ción ellos mismos habían comenzado a no entender, vaciándola poco a poci de su contenido moral" (México en una nuez, IX, 42).

${ }^{116}$ IX, 47-48.

$117 \mathrm{XI}, 51$.

$118 \mathrm{XI}, 126$. Desde presupuestos afines, Henríquez Ureña escribió $\mathrm{s}$ Plenitud de España (ensayos reunidos en 1940 y, ampliados, en 1945).

${ }_{119}$ XI, 144-145. Por eso en estos lugares no acepta la decadencia de Es paña y la culpa de América "en la acusación y en el denuesto", el retras —dirá- "de las especies espirituales" con respecto al mestizaje biológico.

120 Nada tiene que ver con mi objeto La imagen de América de Alfonso Rey, (Madrid, 1955) de Rafael Gutiérrez Girardot, reimpresa en 1962 con . estudio de Ingemar During, "Alfonso Reyes helenista". Sin embargo, es irr prescindible leer en este sentido la primera parte del libro de PEDRO HenR QUEZ UREÑa, Ensayos en busca de nuestra expresión (cit. en n. 11), que, en la ed ción que manejo, va precedido de la Evocación que escribió don Alfonso, tiene (p. 142) una importante referencia bibliográfica. 
además, mozos de su edad que acabarían siendo grandes maestros de ciencia.

En su Monterrey natal supo de España y de la literatura española. En días que para cualquiera serían de aprendizaje, él alcanzó granazón; supo separar el grano de la paja y aun valorar con enorme originalidad. Así descubrió la tradición y así supo - ¿cuántos años de adelanto? - estimar lo que había de genial en la poesía de Góngora. Más aún, se salió de los caminos trillados para estudiar autores para quienes no valen los tópicos, ni los juicios apresurados, y los situó en un amplio marco cultural de proyección europea. Lo que añade sorpresa tras sorpresa a lo que acertamos a leer.

Con este bagaje in ${ }^{-1}$ ectual y con este amor aprendido en los libros, Alfonso Reyes llegó a España en 1914. Aquí estaba en pleno apogeo la llamada generación del 98, aquí florecían, deslumbradores, los novecentistas. Pronto supo juzgar y pronto fue uno más de aquellos hombres singulares ${ }^{121}$. Su presencia tuvo diversos actos: el año de su llegada, la escuela española de filología alcanzaba madurez al iniciar la publicación de la Revista de Filología Española. Alfonso Reyes fue llevado por Federico de Onís al Centro de Estudios Históricos y allí trabajó cinco años con los grandes maestros de primera hora y con los jóvenes de su edad; dos nombres permanecerían para siempre en sus evocaciones: Pedro Henríquez Ureña y Antonio G. Solalinde ${ }^{122}$. De aquellos trabajos le quedó no sólo el rigor de la propia investigación, sino un

121 Probablemente son de 1918 estas palabras de justa valoración: "La guerra hispanoamericana de 1898 ha sido una guerra históricamente fecunda. Trajo la independencia de Cuba; y a cambio de ella, dio a España una visión clara y profunda de su política presente, una severa valoración de su pasado, un admirable estímulo de renovación para el porvenir que los americanos consideran con respetuoso entusiasmo. Por otra parte, trajo también la anexión yanki de Puerto Rico y Filipinas. Cinco años más tarde, los Estados Unidos rechazan y sustituyen toda influencia europea en la república de Santo Domingo" (IV, 158). Sobre lo que digo en el texto, quisiera reforzar mi juicio con la opinión de HenRíQuez UREÑa al situar, puntualmente, el significado que tuvo la presencia de Alfonso Reyes en Madrid (Mi España, ya cit., p. 57).

${ }^{122}$ Discrepó con algunos de los métodos que algo después se pusieron en boga, concretamente con la estilística. Escribió en 1939 en El reverso de un libro. (Memorias literarias): "Montesinos se deja llevar juvenilmente por la seducción de cierta técnica - la que aprendíamos en el Centro de Estudios Históricosy tacha lo que está fuera de ella, como los procedimientos interpretativos de Icaza" (XII, 228). En El deslinde explayaría estas cuestiones. 
sentido muy claro de lo que debe ser una revista científica. $\mathrm{Mu}$ chos años después, lo evocaría en emocionadas páginas.

Pero si en el Centro adquirió la perfección del trabajo riguro so y el contacto con problemas a los que antes no se había asoma do, sus colaboraciones con las editoriales Calleja y La Lectur: proyectaron su quehacer hacia un público mucho más dilatad que el de los especialistas y, sobre todo, el encuentro con Orteg sirvió para dar una personalidad a su forma de ser periodista, ri gurosa, trascendente, bellamente literaria. Ortega no sólo fue $\epsilon$ hombre generoso que le prestó ayuda, sino la presencia eficaz pé ra que se perfeccionara aquel "arielismo" que había aprendid en Rodó. Pero, adẻmás, son los años de las preocupaciones espé ñolas de Ortega y su primer viaje a América con lo que Alfons Reyes dio una nueva dimensión a su quehacer: no se interesó pc las cosas de España, sino que, en todo, fue un español más, y n renunció a decir de su carácter excepcional. Que además esto sirvió para que las gentes de este solar se acercaran a las del Nur vo Mundo, consta con evidencia.

Alfonso Reyes había ido adquiriendo un amor que no era si lo intelectual, libresco, sino forjado por la convivencia, el est: con las gentes, el pisar la geografía. Y junto a Ortega, con otrı matices, pero entrañados en su obra -y en su estilo- estak Azorín. ¡Cuán lejos Alfonso Reyes de la España tétrica de Ve haeren o Regoyos o Solana! ¡Cuán junto a las claridades qı Azorín nos enseñó a ver! Que sus recreaciones de los clásicos y visión sensitiva de la historia no poco deben al maestro de $L$ pueblos. Más aún, cuando tiene que definir a Castilla lo hace cr los primores literarios y la enamorada pasión que están en Espa clara $^{123}$.

Alfonso Reyes está con nosotros para siempre ya. Los band zos de la historia podrán alejarlo, pero su corazón ha queda prendido en todas aquellas gentes que tienen nombres y apellid o que verbenean en oscuro anonimato. $\mathrm{Y}$ ha quedado prendi en las arrugas viejas de Castilla, y en las parameras, y en tierras jugosas, y en los pueblos enjalbegados, y en las ciudac incomparables... salvo con su Monterrey natal. Pero eso, trascenderse gentes y paisajes, intentará defender gallardameı lo que cree que no debe ser una renuncia para ningún mexicaı

${ }^{123}$ Lo dijo en sus versos (p. 61): "Quéjome, España, de ti. / ¿De Coridón, por qué? / -Con tu orgullo me encendí, / con tu humildad me $\mathrm{q}$ mé: / cenizas soy del que fui". 
si es que no quiere dejar de serlo. Las culpas no están solas en un platillo de la balanza, si el anacronismo no queremos que nos quite rigor ${ }^{124}$; ni se pueden cerrar los ojos a lo que, siglos después, resulta evidente ${ }^{125}$; ni se debe considerar como un valor lo que no es sino garrulería ${ }^{126}$. Por el contrario, nuestra unidad es el único programa viable para cada uno de los pueblos del mundo hispánico y para el conjunto de nuestra comunidad:

Las literaturas hispanas, de Europa y de América, no representan una mera curiosidad, sino que son parte esencial en el acervo de la cultura humana. El que las ignora, ignora por lo menos lo suficiente para no entender en su plenitud las posibilidades del espíritu; lo suficiente para que su imagen del mundo sea una horrible mutilación [...] El que las ignora está fuera de la cultura ${ }^{127}$.

Alfonso Reyes nos ha legado unos saberes generosísimos: Grecia siempre ${ }^{128}$, las culturas modernas, desde joven, España. Vino aquí, vivió entre nosotros y fue uno más en sus amores y en la dedicación de su trabajo. Siempre vivió con la misma creencia en las posiblidades de nuestros pueblos y sus palabras - desde la sofrosyne clásica- fueron sencillas, ponderadas y verdaderas. El sufrimiento le hizo entender la dignidad del hombre y los hombres le respetaron. Venía de México y sabía muy bien lo que la historia había hecho sufrir a su gran pueblo y aquí entendió mejor nuestros dolores y las enseñanzas, no diré ajenas, le sirvieron para comprender las propias. Su voz tuvo siempre el hermoso sonido de la fe y de la esperanza. En ellas quiero amparar mi visión enamorada de México y mi pasión española.

Manuel Alvar

Real Academia Española State University of New York at Albany

124 “'La gente conquistadora ¿qué había de cuidarse de respetar los documentos de aquella vetusta poesía [náhuatll, cuando los mismos tlaxcaltecas, aliados del invasor, dieron fin a los archivos de Texcoco y Tenochtitlán", (XII, 283).

${ }^{125}$ Véase supra y las hermosas páginas sobre el Valor de la literatura hispanoamericana (XI, 126-135).

126 Sobre una epidemia retórica (IV, 350-351). Véase, también, la censura de la falsa generalización del "tropicalismo"' (XII, 168).

$127 \mathrm{XI}, 131$.

${ }^{128}$ Después de su regreso definitivo a México (febrero de 1939), volvió a sus viejos amores (XIII, 8). 


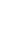

